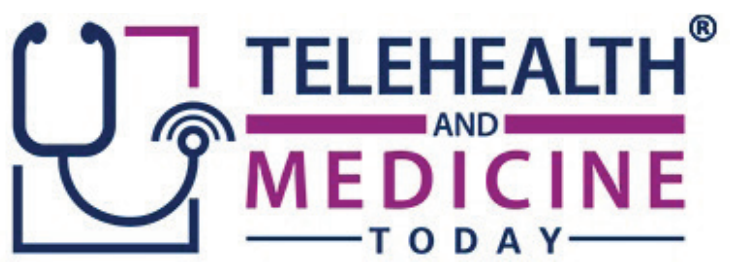

\title{
ConV2X Innovation Ignition Competition: A Behind-Scenes Discussion with Innovators in Healthcare in Technology
}

John Russo, Jr. ${ }^{1}$

Author: ${ }^{1}$ Managing Editor, Telehealth and Medicine Today and Blockchain in Healthcare Today

Corresponding Author: John Russo, Jr., Email: jr@medcomres.com

Keywords: Blockchain, ConV2X Conference, Health Technology, Innovation Ignition Competition, Startups, Telehealth

Section: Perspective, Opinion, and Commentary on a Current Trend or Issue Impacting the Sector

\section{$\mathrm{T}$}

The Second Annual Innovation Ignition Competition 2018 was held during the Converge2Xcelerate (ConV2X)

Conference in New York City. The objective of the conference was to accelerate healthcare's pragmatic adoption of new technology by informing, inspiring, and debating the role and value of technology innovation for health systems, health workforce, and patients around the world.

The competition invited entries focusing on the following areas:

- Reducing health systems and patient out-ofpocket costs

- Designing for the level of a patient's mobility

- Educating patients on new technology, use, application, and outcomes

- Enhanced standard of care for care-giving, remote care, elderly care, and urban care
Applicants demonstrated how their products and services directly impact the telehealth and blockchain health technology sectors (Table 1). Products/services had to be General Data Protection Regulation (GDPR) and/or Health Insurance Portability and Accountability Act of 1996 (HIPAA) compliant. Contestants submitted detailed applications from which judges selected eight finalists for a 5-minute lightning round pitch conducted at ConV2X.

\section{ABOUT THE WINNERS}

First Place: Happify Health

Happify is a collaboration among scientists, researchers, healthcare clinicians, and digital and gaming experts, with the goal of supporting emotional health needs across the continuumfrom well-being and prevention to diagnosable mental health conditions. Designed to fit into an individual's busy life with personalized bite-size activities, Happify offers more than 60 different 
Table 1. Finalists in the Second Annual Innovation Ignition Competition 2018

\begin{tabular}{|ll|}
\hline Finalists & Website \\
\hline American Telephysicians (ATP) & https://www.americantelephysicians.com \\
\hline BitMED_io & $\mathrm{https}: / /$ www.bitmed.io \\
\hline Cohealth & $\mathrm{https}: / /$ cohealthapp.com \\
\hline Debut mHealth's Debut Protocol & $\mathrm{http} / /$ debutmh.com \\
\hline Digipharm's Reimburse & $\mathrm{https}: / /$ digipharm.io \\
\hline Happify & $\mathrm{https}: / /$ www.happify.com \\
\hline Health Innovation's WillChain & $\mathrm{https://www.willchain.live/}$ \\
\hline Knowmadics & $\mathrm{https}: / /$ www.knowmadics.com \\
\hline
\end{tabular}

tracks, 3,000 science-based activities and games, and 300 guided mediations based on the best practices of gaming science and behavioral therapeutic disciplines, including positive psychology, cognitive behavioral therapy, mindfulness, behavioral activation, and solutionfocused therapy.

\section{Second Place: BitMEd}

Dr Rishi Madhok, a practicing physician, and Bo Vargas, a technology expert, founded BitMED, with the goal of creating a healthcare solution that does not charge for care. BitMEd offers their medical services to patients at no cost, lowering the barrier to entry for medical consultations. In return, patients agree to be open to sharing their medical data with BitMEd partners.

\section{Honorable Mention: WillChain}

WillChain uses distributed ledger technology to ensure that all participants, including the care team, family members, and all the health professionals providing care, see the same data regardless of where they access it. Whenever an update is made to the advance care plan, all participants see the update immediately. WillChain technology alerts Emergency Medical Services (EMS) professionals when they arrive to tend to your emergency situation.
For these and all of those who entered the Second Annual Innovation Ignition Competition, we congratulate and salute your dedication to advancing healthcare.

\section{BEHIND THE SCENES}

Managing Editor, John Russo, Jr., requested Editor-in-Chief, John H. Halamka, to share his experience based on observing the journey of start-ups and advice he gives to entrepreneurs.

“It's extremely common," states Dr Halamka, "for start-ups to pivot many times along the path to viability, as business models are better defined, and customer requirements are better understood. A huge gap spans an idea to a sustainable business. Many start-ups discover their costs exceed customer willingness to pay, or the timing for introducing their new product is not well aligned with the marketplace."

“A successful trajectory,” Dr Halamka continues, "commonly exhibits the following characteristics. Start-ups grow organically as their customers permit. The principals show discipline by not giving away too much equity, and they are decisive in their willingness to 'pull the plug' on questionable products before they consume too much of capital." 
"My first question after I'm introduced to a product or service is, '[w] ho pays for the product?' I've heard hundreds of pitches that implement great technology, but who will pay? Where's the market? Next, I help start-ups produce a Strengths, Weaknesses, Opportunities, and Threats (SWOT) analysis to ensure they have a viable product with a robust marketplace and limited competition."

"Favorite start-ups are easy to list. Identifying those that will excel in the next 3 to 5 yearsthat's another matter. That said, a company, with proper management, that creates products and services that layer on top of existing electronic health records, using open international standards, is positioned well. The United States invested $\$ 35$ billion in electronic health records over the past decade, but most available products are hard to use and time-consuming. Innovators have a window of opportunity. Today, there is huge demand for apps and cloud-based functionality that augment existing electronic health records, not replace them."

"Happify Health was selected, among many high-quality applicants, as the winner of the 2018 ConV2X Innovation Ignition Competition. The U.S. healthcare system has long under-resourced behavioral health, and the ever-growing demand for treatment means that we must consider innovative digital solutions. Trained behavioral health professionals are a scare resource. Tools like Happify are the right approach at the right time."

With that, let's hear from our entrepreneurs.

Dr Russo: Let's start by describing your products. Mr Wasden: HappifyDTx provides digital health interventions that, when completed two- to three times per week, have been shown, through randomized clinical trials, to decrease the symptoms of stress, anxiety, and depression and improve resilience of users by $25-30 \%$.
Our interventions are developed in partnership with leading clinical researchers and are based upon the application of positive psychology, cognitive behavior therapy, and mindfulness.

We have had 4 million people use our therapy to improve their mental health, and we work with pharmaceutical companies, health systems, health plans, and employers to improve the mental health of their patients, members, and employees.

Dr Houston: HPEC is a Self-Sovereign Identity wallet for physicians to store authenticated documents and validated credentials. The identity will also be attached to a secure governance and censorship-free communications platform.

Mr Ewing: Strannik was developed by the brilliant medical doctor, physicist, and mathematician, Dr Igor Gennadyevich Grakov. It originated out of a research program into the medical application of industrial lasers in the early 1980s and meets the key aims and objectives of the European Commission's $€ 1.2$ billion-funded Human Brain Project, ${ }^{1}$ whose main objectives are the following:

1. A greater understanding of what the brain does and how it does it.

2. The relationship between brain function and pathological onset and how this could be applied (e.g., to develop a new generation of cognition-based diagnostic technology that determines the pathological correlates of complex medical conditions such as Alzheimer's disease).

3. A unified, multi-level understanding of how the human brain integrates the flow of pathological data from the visceral organs and how this could be applied with therapeutic effect. This is completely unprecedented in modern medicine. 
It is a digital, cognitive, games-like techniquethe first medical technology to incorporate a precise and sophisticated simulation of how the human brain regulates the body's function. It is available via a PC and as an online system Software as a Service (SaaS). It does this by advanced mathematical modeling that incorporates such understanding into the screening and treatment of common life-stylerelated morbidities. It comprises two basic elements: the medical screening modality Strannik Virtual Scanning and the neuromodulation technique Strannik Light Therapy.

It would be used by the patient and/or the doctor. About 20 in-market surveillance studies involving 6,500-9,800 patients have confirmed that Strannik Virtual Scanning is 2-23\% more accurate than the entire range of diagnostic technologies widespread in the clinics and hospitals, and that Strannik Light Therapy is $75-96 \%$ effective depending on the patient's health (drugs are approximately $50 \%$ effective.) $)^{2}$ More information is available at www. montaguehealthcare.co.uk.

Mr Gasztonyi: Our product, $360^{\circ}$ Aware ${ }^{\mathrm{TM}}$ by Knowmadics, is an Internet-of-Things (IOT) software platform that can connect to multiple devices for use in home healthcare and personal monitoring. The platform has two components - a mobile IOT integration and collection and notification applicationsupporting most smart phones and simpler devices like apple watch, and a back-office integration and management server for interoperability with data stores Electronic Health Records (EHRs), decision support (e.g., Computerized Physician Order Entry [CPOE], case management tools, and response systems), and business intelligence analysis tools. It is currently deployed globally for several missions in public safety, and as such provides a coordinated response platform in cases of emergency response to homebound, disadvantaged, and remote patients.

It has an open application programming interface/software development kit (API/SDK), which allows hardware manufacturers to connect directly to the platform supporting notifications/ alerts and machine-to-machine (M2M) interaction between devices. So, for example, a home breathing monitor could be connected to a home camera system with one's mobile phone so that when a patient suffers distress, the system automatically notifies the response team/family members. In addition, the ecosystems mobile application is supported by a response/client support center integration platform that allows other existing systems to exchange information for situational awareness (location and status) and response, as well as business intelligence (BI) data integration. This allows, for example, care staff, in a home care or ambulatory care environment, to have an integration of their task management tools with home monitoring device(s), patient environmental factors, and all for a pull-push of information to/from the patient and case/care provider.

Our software was designed to be "white-labeled" so that hardware manufacturers can maintain their branding and customer intimacy. From its inception, the $360^{\circ}$ Aware ${ }^{\mathrm{TM}}$ product has included high-security data collection and transmission technologies and is fully compliant of the HIPAA security requirements.

\section{Dr Russo: What inspired you to launch the product?}

Dr Houston: Many things, but primarily an experience I had as a physician where a hospital stole my identity and was billing charts under my name. I realized blockchain identity solutions could prevent this from happening again. 
Mr Gasztonyi: The mother of the founder and CEO of the company, Paul Maguire, was diagnosed with terminal cancer. She wanted to stay in her home as long as possible without having "strangers" coming and going. The situation also highlighted the need to improve interoperability between stovepipe remote monitoring systems provided by various vendors and a method to help streamline and evolve workflows for care providers dealing with the elderly, the disadvantaged, and remote populations.

Mr Wasden: After selling a successful casual video game company, we decided to start a video game company that would apply the science of engagement, positive psychology, mindfulness, and cognitive behavior therapy to improve mental and emotional health.

Mr Ewing: We launched Mimex Montague Healthcare in order to commercialize Strannik on the international medical markets. In 2003, we demonstrated Strannik to the medical director of the Queen's Medical Centre, Nottingham. He was astonished that "a computer program" could give such a complete and accurate assessment, correctly diagnosing the five to six conditions affecting the test patient. Our first patient had dysarthria. He had not spoken for 5 years, except in guttural noises. Everything that biomedicine had offered had been unsuccessful. Strannik light therapy corrected his condition in 6 days.

Dr Russo: What has been the most frustrating experience or barrier to date, and how have you grappled or are grappling with it?

Mr Gasztonyi: The technology was originally built for public safety and surveillance. It is very difficult for companies not established in the home healthcare or telehealth vertical to break into this market segment. Mr Ewing noted the importance of personal networking in this field. I concur and will add that finding a launch customer outside your "friends and family" is hard.

We believe it requires an ecosystem of outside innovative technology companies, working with payers, providers, and established "current state" service companies, to meet the market demands and challenges posed by increasing healthcare costs, an aging population, and overall stress on existing provider systems.

Mr Wasden: Healthcare is an industry that is notoriously hard to change. While patients are fairly eager to change their practices and try digital therapies, health plans and healthcare providers are much more skeptical and less willing to try something new and innovative. Having said that, we have four or the five largest health plans as our customers.

Mr Ewing: The most significant barrier is the lack of understanding by the medical community and/or the threats that such a radical and disruptive technology poses to established ways of providing healthcare. We continue to build the evidence base in order to persuade key decisionmakers about the value of such a technique.

Dr Houston: Many physicians think blockchain is a scam, and they do not like technology. They agree with the problem, but it takes time for them to understand how this is a solution.

Dr Russo: What is the most valuable failed experience you have had?

Mr Gasztonyi: I agree with Mr Wasden's analysis of the healthcare industry. Trying to approach insurance companies with this idea as an extension of their coverage in support of clients seemed like a "good entry strategy." However, so far, it has not been the case. Insurance company executives worry about "liability" relative to protecting the information 
and their duty of care if someone was to signal distress or panic and they were not able to get a response in a timely manner.

It is frustrating that people are "willing to do nothing" rather than attempt to innovate because of the liability that might be engendered. This seems to be a cybersecurity risk that exists because payers are perhaps a bit behind in dealing with risk and the associated risk management within the sharing of data/information. It must be noted that many lessons are learned from law enforcement and intelligence community regarding how to protect information, yet organizations still share it.

Mr Wasden: We have learned a lot from observing the innovative efforts of WellDoc in the digital therapeutic marketplace. They have attempted to pursue almost every business model imaginable, including direct-to-consumer (DTC), prescription-only, paid like a drug, paid like a medical device, etc. After nearly 10 years of experimentation, none have worked well, yet.

The reality is that all new innovations require new business models to commercialize them. It takes at least a decade of business model experimentation to find what will work in order to scale the new technology.

Mr Ewing: Our most valuable failed experience was to fail to respect the need for regulatory compliance, particularly so in the period 2007 through 2010.

Dr Houston: I approached the leader of a physicians group hoping to work together, only to be turned away. It was eye-opening and made me realize that I need to listen first and not judge a book by its title.

Dr Russo: Where are the women in the sector? Mr Ewing: We cannot speak about women in the wider sector other than to comment that it is dominated by men. Mimex Montague Healthcare has two prominent women in the management team-Dr Yulia Borovleva (neurologist) and Dr Elena Ewing (ophthalmologist).

Mr Wasden: Women comprise over half of the members of our team. Our chief scientist, head of content strategy, chief commercial officer, most of our marketing team and customer support team are women.

I think few women presented during the Converge2Xcelerate Health-tech Modernization Conference because they are not as often the founders of businesses or leaders of a business division.

Mr Gasztonyi: Our entire C-Suite, outside of the CEO, Paul Maguire, are women. The cofounder and President Claire Ostrum, our head of operations, CFO, head of sales, and west coast technical support team are all women. They comprise $40 \%$ of our staff.

We noticed the lack of participation as well, and it is concerning. Unfortunately, our senior staff all have "real jobs" and could not take a day and a half out of work to travel to New York City for a 5-minute presentation. However, they did drive our presentation, and they are available for client/ partner discussions.

Dr Russo: How would you describe the journey of a start-up?

Mr Gasztonyi: For our CEO, this is his third company, and my fourth. Being involved from a "Napkin-to-a-C-Corp" is a unique experience, but one not for the faint of heart. Other people in the organization have start-up to operational to exit-experience. They all agree that it is challenging, frustrating, fast paced, and truly emotionally rewarding. 
Mr Wasden: Our founders lacked healthcare experience, and we initially approached our venture as a direct-to-consumer business because that is what we knew from our video game business.

As we decided to become more healthcarecentric, we had to add talent with health plan, health provider, and pharma experience. Now, we are primarily an enterprise business with our DTC business being very small.

Mr Ewing: With 20/20 hindsight, looking back to 2003, had I known the difficulties waiting to be encountered, I would probably have declined the opportunity. It is important to go into this field with an understanding that many challenges must be overcome in order to eventually "succeed."

Dr Houston: There is a solution that is found for a problem that previously did not have a solution (or the solution was inadequate). That solution is launched into the world by someone who truly understands the problem and how important it is to solve it. Some see the problem, some see the solution, but if that person is able to make enough people see both, then the start-up will succeed.

Dr Russo: Have you experienced a point that changed the trajectory of your journey?

Mr Wasden: After we had 3 million people use our solution with our DTC model, healthcare payers, providers, and pharma companies approached us and convinced us to pivot towards the enterprise market.

Mr Gasztonyi: Yes. We raised most of the initial start-up capital for $360^{\circ}$ Aware ${ }^{\mathrm{TM}}$ by Knowmadics around buying a company and then transitioning into multiple vertical spaces. Four days before we were to close on that transaction, the target company decided to take our business plan and execute it themselves and called off the sale. That forced us to rethink our strategy, calm our investors (which were our family members). In the long run, that initial pivot has made all the difference for our team.

We now own more of the entity than we would have. Culturally, we were able to start before people knew how successful it could be and hire the types of employees who shared our vision, rather than inherit employees who had been working under a different structure for a decade.

Dr Houston: I originally wanted this to be a humanitarian effort, but I realized in order for it to have a true impact it would need to generate revenue, so I found a way for it to generate revenue and changed the model a bit.

Mr Ewing: The exact event and time are difficult to identify. Perhaps the market is changing in our favor. There is ever-increasing recognition of the limitations of biomedicine and the need for technologies, which reduce the complexity and cost of healthcare.

Dr Russo: What one pearl of advice would you offer someone with an idea?

Dr Houston: Don't get discouraged, but move on if the beta test fails.

Mr Wasden: Test it with consumers quickly and iterate quickly to improve it. Too many companies in the digital health space focus on the enterprise market. They take too long to get their product in front of lots of people to test it.

Mr Gasztonyi: Perseverance. In a small business, particularly a "start-up," there are a lot of dark days. You must be able to get up every day, 7 days a week, 20 hours a day sometimes, and grind it out. Everybody is looking to you. If you stop believing, if you stop trying, 
everybody you have brought along on your vision quest will stop believing and stop trying.

Mr Ewing: I agree. If you believe in your idea/ product, stay committed. Stay strong.

\section{Dr Russo: How important is a team to the process?}

Mr Gasztonyi: The team is most important. There are no such things as self-made successes or people. It is the people you surround yourself with - partners, employees, investors, and a board of directors - who make it happen.

People do not buy things from companies, people buy things from people. Everybody you hire in a small business becomes a reflection on what type of business "you are." So, creating the right team and being open to walking away from someone or risk everything to get someone is your most important role in a company.

Mr Ewing: Having a team enables you to have the personal support from your colleagues, to have people against whom you can bounce ideas, and who can offer their expertise and knowledge. "No man is an island."

Mr Wasden: We have a diverse team representing many different disciplines, both healthcare and non-healthcare, and that makes a huge difference.

Dr Houston: They are 98\%. This is nothing without them.

Dr Russo: How are you monetizing your effort? Mr Gasztonyi: We monetize our effort through subscription services.

Most people in our space are giving away technology and monetizing their effort(s) by reselling client data. We are exactly the opposite.
Five years ago, when we started the company, telling people that "privacy was part of our service" did not resonate with them. However, considering what is going on with the daily reports about what "App" companies are doing with "your data" has made people realize the advantage of using our solution.

Mr Wasden: We have many different business models. For DTC, we have a freemium model. With health plans, we have per member per month (PMPM) model. With pharma and the Food and Drug Administration (FDA), we have several different models, including a non-FDAcleared version for patient support programs and marketing. We will have FDA-cleared version for a prescription-only version that will be reimbursed.

Mr Ewing: Radical and disruptive technologies complicate the monetizing process. The gains can be immense, but so too can be the threats and obstacles. To date Mimex Montague Healthcare is self-funded by the co-owners the Grakov and Ewing families.

\section{Dr Russo: What inspired you to enter the competition, and how will it help your efforts as a start-up?}

Mr Gasztonyi: I have 15+ years of experience in healthcare, primarily in interoperability and workflow optimization. We knew Knowmadics was missing an opportunity to get exposure in the healthcare vertical, and ConV2X was the vehicle to get the exposure we needed. My submission basically tells the story of why I believe Knowmdics should be strongly considered in any healthcare ecosystem that wants to help in the growing telehealth market. We made the submission, and, lo and behold, we made it to the final round.

We hope it helps in three key areas: exposure (allow the market to know mobile interoperability 
in healthcare is here today), partnering (build the ecosystems, save money and time, and impact patient care results while gaining provider/payer efficiencies and economic benefits), and attract a pilot program (prove the value for patients, care providers, and the community).

Mr Wasden: We have raised $\$ 30$ million in venture capital financing so far and have decided to start our next round of fund-raising. We thought this might offer good exposure.

Mr Ewing: We have entered many challenges and competitions and will continue to do so in order to bring attention to our technology and the benefits it can bring to everyone.

Dr Russo: Do you subscribe to Telehealth and Medicine Today or Blockchain in Healthcare Today? Why?

Mr Wasden: Yes. I am on the advisory board.

Mr Gasztonyi: We use the Telehealth and Medicine Today website as an excellent source of information and the pulse of new thinking in healthcare.

\section{CONCLUSIONS}

Mr Gasztonyi: There has never been a better time to create a small business around technology. More and more of the costs associated with starting a business like ours have been reduced because of technology innovations.

The goal is to take advantage of as many of those innovations as possible and make yourself as open a platform as possible to be able to attract interest in breaking into multiple verticals.

From this competition, we learned a tremendous amount about what is going on in the market. We believe that our model going forward will work.

Mr Wasden: We seek to transform the practice of medicine by enabling payers, employers, providers, and pharmaceuticals to address stress, anxiety, and depression associated with the vast majority of diseases that people suffer from through digital activation, engagement, and management.

Dr Houston: Physicians have always had the trust of their patients, but that trust is being eroded by the current healthcare delivery model, where overall both physicians and patients no longer have a choice. The majority of healthcare decisions are now made by a third partywhether it be a health system, an insurance company, or, in most cases, a combination of both. HPEC will address all of the above issues and fix the user experience for physicians by putting physicians in control of healthcare decisions again. When the physician-patient relationship is preserved in a decentralized digital space, it will reverse this trend of health system consolidation, alleviating the current crisis of trust in healthcare.

\section{SPECIAL THANKS TO OUR JUDGES} Partners in Digital Health greatly appreciates the contributions by those listed below who contributed their time and expertise in judging the ConV2x entires.

Gil Alterovitz, PhD, Faculty, Harvard Medical School/Boston Children's Hospital, Massachusetts Institute of Technology, Harvard Medical School

Bryan Arkwright, Managing Consultant/ Professor, Schumacher Clinical Partners/Wake Forest University School of Law

Karim Babay, CEO and Chief Investment Officer, Intrinsic Value Investment Partners

G. Anton Decker, President, Health Innovation, Bon Secours Mercy Health 
Gary German, Founder and CEO, Nonnatech

John D. Halamka, MD, MS, CIO, Beth Israel Deaconess Medical Center, Chairman, New England Healthcare Exchange Network (NEHEN), Co-Chair, HIT Standards Committee, Professor, Harvard Medical School, Beth Israel Deaconess System

Fennie Wang, COO and Chief of Regulatory, OpenWater Capital.

\section{REFERENCES}

1. Human Brain Project wins major EU funding. UCL News. 2013 [Accessed 4/2/19]. Available from: https://www.ucl. ac.uk/news/2013/jan/human-brain-projectwins-major-eu-funding

2. Spear BB, Heath-Chiozzi M, Huff J. Clinical application of pharmacogenetics. Trends Mol Med. 2001;7(5):201-204.

Copyright Ownership: This is an open access article distributed in accordance with the Creative Commons Attribution Non Commercial (CC BY-NC 4.0) license, which permits others to distribute, adapt, enhance this work non-commercially, and license their derivative works on different terms, provided the original work is properly cited and the use is noncommercial. See: http://creativecommons. org/licenses/by-nc/4.0. 